\title{
Examining Contextual Factors and Individual Value Dimensions of Healthcare Providers Intention to Adopt Electronic Health Technologies in Developing Countries
}

\author{
Yvonne O' Connor ${ }^{1, *}$, Stephen Treacy ${ }^{2}$, and John O' Donoghue ${ }^{1}$ \\ ${ }^{1}$ Health Information System Research Centre, University College Cork, Ireland \\ \{y.oconnor, J.odonoghue\} @ucc. ie \\ ${ }^{2}$ Business Information Systems, University College Cork, Ireland \\ s.t.treacy@umail.ucc.ie
}

\begin{abstract}
Despite substantial research on electronic health (e-Health) adoption, there still exist vast differences between resource-rich and resource-poor populations regarding Information Technology adoption. To help bridge the technological gulf between developed and developing countries, this researchin-progress paper examines healthcare providers' intention to adopt e-health technologies from two perspectives 1) contextual factors (i.e. specific to developing world settings) and 2) individual value dimensions (i.e. cultural, utilitarian, social and personal). The primary output of this paper is a theoretical model merging both the contextual factors and value dimensions; this forms a strong baseline to examine and help ensure the successful adoption of e-Health technologies within developing countries. Future research will be performed to validate the model developed in this paper, with a specific focus on mobile Health in Malawi, Africa.
\end{abstract}

Keywords: Contextual Factors, Individual Value System, Developing Countries, Theoretical Model.

\section{Introduction}

A vast array of research exists which examines the adoption of Information Technology (IT) at various levels of analysis in both developed and developing regions, with the former dominating extant Information Systems (IS) research. In recent years, academics have focused their research attentions on the implementation of IT in developing regions, i.e. countries operating within Information and Communication Technology (ICT) resource-constrained conditions and where the population has limited knowledge in utilising ICT solutions [1]. Adoption levels of IT in resource-poor regions continue to lag behind their richer region counterparts $[2,3]$, particularly in the health care domain [4]. The need for reforming the delivery of healthcare services to accommodate the needs of modern societies is driven by unprecedented health inequities between the poor and wealthy economies.

\footnotetext{
* Corresponding Author.
} 
A significant amount of literature focuses on intentions to adopt technology in the e-health domain. Despite the contributions of such studies, there still remains a high failure rate of e-health technologies in developing regions [5], due to the lack of adoption [6]. Understanding why people accept or reject information technology is the first step toward finding a solution to the problem [7]. Such failure rates imply that more effort is required to fully understand this research domain and that additional factors exist which were previously undocumented in extant literature. However, more attention is required to examine the human, as opposed to technical, aspects associated with e-health implementation initiatives [8].

Extant research shows that factors which effect the adoption of IT in western societies may not have the same influential impact on IT adoption in developing regions $[9,10]$. The rationale is that the contextual landscape and individual values differ across both populations [11, 12]. First, the very concept of value has been defined as "the worth, desirability or utility of a thing" [13] and it has been measured and explored at various levels of analysis. However few authors would contend that the search for value has reached a point where both theoreticians and practitioners are satisfied with its outcomes [14], as the worth/desirability/utility to a targeted user depends on many factors [13], for example transparency and ease of access. A review of extant literature also shows a wide array of opinions as to what value actually entails, with no unanimously accepted definition. As a result, authors often seek to interchange the term with other concepts such as impact [15], influence [16], quality [17], success [18], and effectiveness [19]. It should not be surprising therefore that investigating value creation from emerging ICTs is a complex phenomenon, involving the simultaneous presence and interaction of various exogenous and endogenous factors.

Developing from the various disagreements between authors surrounding their approach of theorising value, there is a consensus that value creation starts with identifying the perceived value that is being offered to the end user by the project in question [14]. Hu et al. [20] define perceived value as the intended user's "perception of the net benefits gained in exchange for the costs incurred in obtaining the desired benefits" (p.4). Despite various definitions of perceived value, there exists general acceptance that it: a) is linked through the use of some product, service or object; $b$ ) is subjectively perceived by users, rather than objectively determined; and c) involves a trade-off between what the user receives and gives to acquire and use the product or service [21]. From this synopsis, the locus of potential value in e-health technologies can be identified where there exists the opportunity for the users involved to obtain desired results. Multiple loci (cultural, utilitarian, social and personal) have been therefore identified for the successful adoption of e-health technologies in developing countries.

Second, when examining an end users' rationale for adopting e-health technologies in developing countries it is important that the contextual landscape along with the perceived value is taken into account. For example, existing researchers [cf. 22] argue for the significance of examining context but rarely portray its importance. Exploring the contextual landscape is imperative as it reflects external elements that comprise 
the environment or conditions for decision making tasks [23], which may be outside of the researchers' control. Yet, a dearth of research exists which examines the impact contextual landscape and individual values have on behavioural intentions to adopt e-health technologies in developing countries. The authors argue that it is imperative to examine this unexplored area in extant literature to obtain richer insights into the intentions to adoption e-health technologies in resource poor countries.

The objective of this study is to develop a theoretical model which explores the drivers of e-health technology adoption from a contextual and value dimensions perspective. The authors observe that exploring contextual factors in association with an individual's value system may help enhance current knowledge on health care providers' intentions to adopt e-health technologies in developing countries.

This paper is structured as follows: In an effort to bridge the research gap highlighted previously, a theoretical model and three propositions are presented in Section 2. This theoretical model, which draws upon and extends extant literature, is proposed for future research. Section 3 outlines the proposed research methodology which will empirically examine the newly established theoretical model and associated propositions. Section 4 concludes by presenting the key implications of this study for theory and practice.

\section{Theoretical Model Development and Propositions}

This paper seeks to provide richer insights into healthcare providers' (referred to as Health Surveillance Assistants in rural Malawi, Africa) intentions to adopt e-health technologies. A theoretical model (see Figure 1) is presented which will be used to explore this phenomenon. This model, developed by adopting and extending extant literature will be explained in the following section, beginning with the rationale underpinning each construct and proceeding to the development of three propositions.

\subsection{Contextual Factors}

Contextual factors have been found to influence the intentions to adopt an innovation at various levels of analysis (i.e. individual, firm/organisational, and national). Contextual factors influence one's decision making behaviour [23] which can vary across populations and industries.

According to extant literature [24, 25, 26, 27], important differences exist between healthcare and other industries (e.g. manufacturing, financial, aerospace). First, Chiasson et al. [25] argue that healthcare represents a markedly different social and technical context compared with many of the industries where IS research is conducted. Second, it is argued that the special characteristics of healthcare functions, processes and organisations are another difference which distinguishes it from any other service sectors or industries, with healthcare being a highly customised, complex relationship (person-to person), contrary to banking or insurance industries [24]. 
The healthcare context in resource-poor regions is more complex than developed countries due to uncertainty surrounding lack of resources (financial, technical and human). Therefore, the contextual factors for e-health technology adoption in developing countries differentiate this research from previous studies examined in developed countries. Several authors have concluded that value conceptualisations may vary depending on a study's context $[28,29,30]$. As a result, it is proposed that:

\section{P1: Contextual factors in developing countries impact Healthcare Surveillance Assistants' value system.}

\section{P2: Contextual factors impact Healthcare Surveillance Assistants' to adopt e-health technologies in developing countries.}

\subsection{Individual Value System}

Defined as "an organized set of preferential standards that are used in making selections of objects and actions, resolving conflicts, invoking social sanctions, and coping with needs or claims for social and psychological defenses of choices made or proposed" [31], an individuals' 'value system' comprises of a cluster of combined values which influences individual behavior [32]. For this paper, an individual value system comprises of cultural, utilitarian, social and personal values (each dimension is described in Table 1). An 'individual' in the context of this paper refers to Health Surveillance Assistants (HSA), whose role in society is described in Section 2.

Culture diversity between developing and developed countries can be observed based on "Individualism versus Collectivism", "Power distance", and "Masculinity versus Femininity" [43]. For instance, resource-rich environments (such as Europe and U.S.A) are driven by individualist approaches whereas developing countries are concerned with collectivist strategies [44].

Utilitarian values reflect functional values which are relevant for task-specific use and are characterised as instrumental and extrinsic [35]. E-health technologies offer an array of services which can assist HSAs in their tasks. For instance, electronic health records provide a digital collection of clinical accounts and diagnostic reports pertaining to an individual patient $[46,47]$ which can assist HSAs when assessing and diagnosing patients. When individual users' perceive that the technological tool could facilitate them when accomplishing tasks, their behavioural intentions towards adopting the IT increases [48, 49].

Social value, as defined in the context of this study, is closely linked to the [37] motivational construct; namely, introjected motivation. This type of motivation identifies the social needs of individuals to obtain social approval from other individuals in society to improve/maintain feelings of worth. Individuals often adopt IT solutions in pursuit of recognition among other individuals and/or based on the influence of 'others', for instance, the social influence of peers, superiors, and family members has been found to directly affect individuals' decision to adopt IT [49],[50],[54]. 
Table 1. Value Dimensions Definition

\begin{tabular}{|c|c|c|}
\hline $\begin{array}{c}\text { Value } \\
\text { Dimension }\end{array}$ & $\begin{array}{c}\text { Definition used for the purpose of } \\
\text { this study }\end{array}$ & $\begin{array}{l}\text { Relevance to Behavioural Intentions to } \\
\text { Adopt e-Health technologies }\end{array}$ \\
\hline Cultural Value & $\begin{array}{l}\text { A set of beliefs and norms that are } \\
\text { both consciously and subconsciously } \\
\text { held by HSA in the given society } \\
\text { (adapted from [33]). }\end{array}$ & $\begin{array}{l}\text { It is unlikely that cultural values can be easily } \\
\text { changed or adjusted to conform to any } \\
\text { changes introduced by new technology. This } \\
\text { conformity, therefore, may have an impact on } \\
\text { individual users' intentions to adopt e-health } \\
\text { technologies [9]. }\end{array}$ \\
\hline $\begin{array}{l}\text { Utilitarian } \\
\text { Value }\end{array}$ & $\begin{array}{l}\text { The degree to which a HSAs believe } \\
\text { that using e-health technologies will } \\
\text { assist in accomplishing his/her goals } \\
\text { (i.e. delivering healthcare services to } \\
\text { patients) in terms of effectiveness } \\
\text { and efficiency (adapted from [34, } \\
\text { 35]). }\end{array}$ & $\begin{array}{l}\text { The utilitarian view is concerned with the } \\
\text { effectiveness and efficiency that result from } \\
\text { the potential use of an IT application [34]. } \\
\text { HSAs perceive utilitarian value from e-health } \\
\text { technologies when such technological tools } \\
\text { facilitate healthcare providers to deliver } \\
\text { healthcare services to patients without } \\
\text { impacting their daily routines. }\end{array}$ \\
\hline Social Value & $\begin{array}{l}\text { The degree to which HSAs perceive } \\
\text { social utility acquired from the } \\
\text { potential adoption of e-health } \\
\text { technologies (adapted from [36]). }\end{array}$ & $\begin{array}{l}\text { It is argued [36] that social value represents } \\
\text { "the preference for certain outcome } \\
\text { distributions between the self and the } \\
\text { interdependent other." As a result, social } \\
\text { value is often established from the use of a } \\
\text { product or service which is shared with other } \\
\text { people [51],[53]. This perspective may have } \\
\text { an impact on HSAs' intentions to adopt e- } \\
\text { health technologies. }\end{array}$ \\
\hline $\begin{array}{l}\text { Personal } \\
\text { Value }\end{array}$ & $\begin{array}{l}\text { Conscious valuing of a behavioural } \\
\text { goal such that the action is accepted } \\
\text { or owned as personally important to } \\
\text { HSAs (based on [27]). }\end{array}$ & $\begin{array}{l}\text { Individual perception that the values } \\
\text { associated with an IT project are similar with } \\
\text { his/her personal goals and identity, thus } \\
\text { viewing the action as personally important } \\
\text { [56], thus increasing likelihood of e-health } \\
\text { technology adoption by HSAs. }\end{array}$ \\
\hline
\end{tabular}

Personal values are conceptualised as deeply-embedded motivational sources and often defined as goals that vary in their importance and serve as guiding principles in people's lives [55]. Personal values therefore are similar to the concept of identified motivation [37]. With an identified motivation, an individual consciously values the collective goal of the IT project and perceives it as his or her own [37],[56], which ultimately can influence e-health technology adoption.

It is evident from the previous sections and Table 1 that healthcare providers' intentions towards e-health technologies can be attributed to various value dimensions which form an individual's value system. As a result, it is proposed that:

\section{P3: Healthcare Surveillance Assistants' Value System impacts their intentions to adopt e-health technologies in developing countries.}

Based on this review of extant literature a theoretical model is developed, consisting of three propositions (Figure 1). 


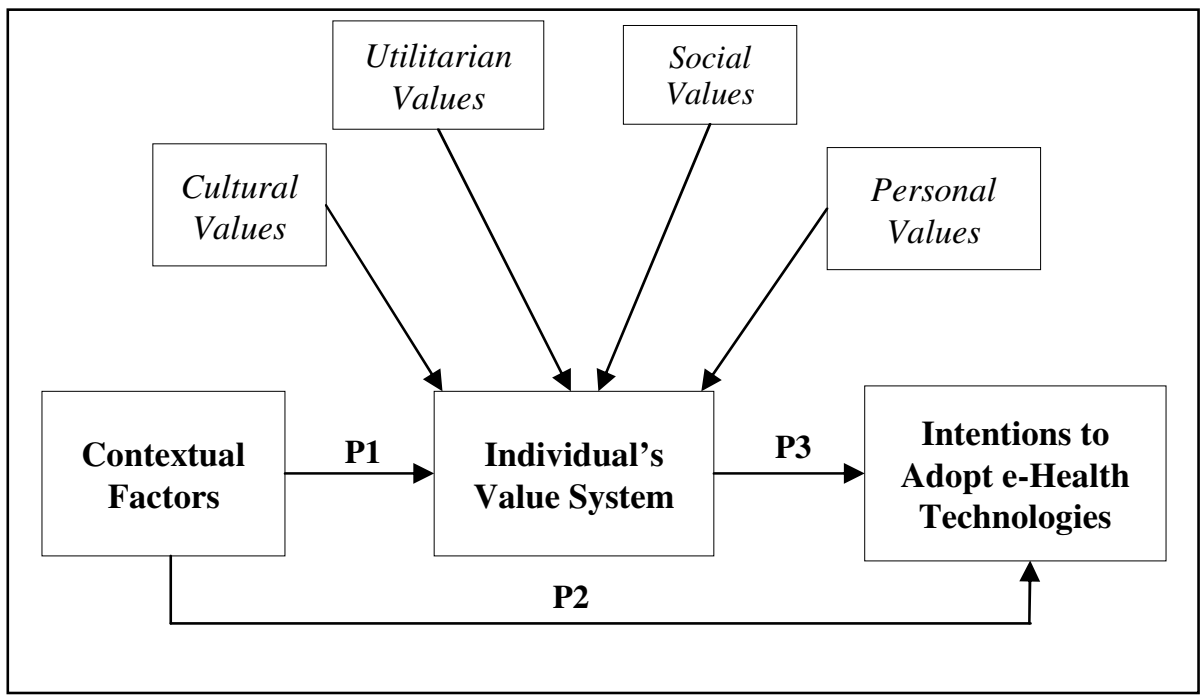

Fig. 1. Theoretical Model

\section{Proposed Methodology}

Future work will empirically examine the theoretical model (Figure 1) by obtaining quantitative data from HSAs (sometimes referred to as Community Healthcare Workers) in Malawi, Africa. HSAs are deployed in rural settings with an assigned catchment area, responsible for preventive health in children. Presently, HSAs utilise a paper-based set of guidelines known as the Case Community Management (CCM), which is a stepwise and structured approach towards assessing and managing children. Attempts are currently underway to digitise this paper-based approach.

To obtain the necessary quantitative data, a paper-based survey is the data collection technique which will be implemented. The survey will be designed adhering to existing guidelines in the IS literature. Measures for each construct highlighted in Figure 1 are reflective in nature and will be obtained from extant literature. The Partial Least Square [PLS] (Structural Equation Modelling [SEM]) approach will be employed to analyse the data. All statistical analysis of the quantitative results will be conducted using SmartPLS (Version 2.0.M3). All reliability and validity test will be performed meeting the integral criteria and their associated threshold levels documented in the IS literature.

\section{Discussion and Conclusions}

The technological gulf between resource-rich and resource-poor populations still exists. To assist in overcoming this real-world problem, developing countries need to leverage their existing ICT resources. To help ensure that a successful adoption of ICT is achieved, greater attention is required to assess contextual factors and 
individual value dimensions of a healthcare provider's intention to adopt e-health technologies. Therefore the objective of this study is to develop a theoretical model which explores the drivers of e-health technology adoption intentions from both a contextual and value perspective.

Values can be difficult to interpret, considering the complexity, significance and meaning that differs from one context to another. There is a real need to examine individual values under a clear set of contextual factors. The primary contribution of this paper is the construction of a theoretical model which will enable multiple individual values to be assessed under different contexts. From this baseline, researchers will be able to assess more accurately a user's intentions to adopt e-health technologies under a variety of contextual factors. The framework is supported by three propositions which are supported based on existing research:

- P1: Contextual factors in developing countries impact Healthcare Surveillance Assistants' value system.

- P2: Contextual factors impact Healthcare Surveillance Assistants' intention to adopt e-health technologies in developing countries.

- P3: Healthcare Surveillance Assistants' Value System impacts their intentions to adopt e-health technologies in developing countries.

While the proposed model has been rigorously developed based on extant literature, its principal limitation is that it has not been empirically examined against a developing world context. Moreover it solely focuses on human/environmental as opposed to technological dimensions, which have been reported to impact intentions to adopt IT in extant literature. Once the data is collected and assessed the proposed theoretical model may be refined to reflect the real-world impact (a) contextual factors in the developing world and (b) associated values have on the intentions to adopt e-health technologies. This research will serve as a basis for future adoption based research within developing countries.

Acknowledgement. The Supporting LIFE project (305292) is funded by the Seventh Framework Programme for Research and Technological Development of the European Commission www. supportinglife.eu.

\section{References}

[1] Ssekakubo, G., Suleman, H., Marsden, G.: Issues Of Adoption: Have E-Learning Management Systems Fulfilled Their Potential In Developing Countries? In: Proceedings of the South African Institute of Computer Scientists and Information Technologists Conference on Knowledge, Innovation and Leadership in A Diverse, Multidisciplinary Environment, pp. 231-238. ACM (2011)

[2] Dasgupta, S., Gupta, B.: Impact of Organizational Culture on Technology Use in a Developing Country. In: ECIS 2012 Proceedings. Paper 240 (2012)

[3] Greenhalgh, T., Procter, R., Wherton, J., Sugarhood, P., Shaw, S.: The Organising Vision for Telehealth and Telecare: Discourse Analysis. BMJ 2, E001574 (2012) 
[4] Li, J., Moore, N., Akter, S., Bleisten, S., Ray, P.: Mhealth For Influenza Pandemic Surveillance in Developing Countries. In: IEEE 43rd Hawaii International Conference on System Sciences, pp. 1-9 (2010)

[5] Heeks, R.: Information Systems and Developing Countries: Failure, Success, and Local Improvisations. The Information Society 18, 101-112 (2002)

[6] Wouters, B., Barjis, J., Maponya, G., Maritz, J., Mashiri, M.: Supporting Home Based Health Care in South African Rural Communities Using USSD Technology. In: AMCIS 2009 Proceedings. Paper 410 (2009)

[7] Al-Gahtani, S.S.: Computer Technology Adoption in Saudi Arabia: Correlates of Perceived Innovation Attributes. Information Technology for Development 10, 57-69 (2003)

[8] Cocosila, M., Archer, N.: Adoption of Mobile ICT for Health Promotion: An Empirical Investigation. Electronic Markets 20, 241-250 (2010)

[9] Al Sukkar, A., Hasan, H.: Toward a Model for the Acceptance of Internet Banking in Developing Countries. Information Technology for Development 11, 381-398 (2005)

[10] Vatanasakdakul, S.: Introducing Cultural Fit Factors to Investigate the Appropriateness of B2b Technology Adoption to Thailand. In: 21st Bled Econference Ecollaboration: Overcoming Boundaries Through Multi-Channel Interaction (2008)

[11] Ahern, D.K., Kreslake, J.M., Phalen, J.M.: What Is Ehealth (6): Perspectives on the Evolution of Ehealth Research. Journal of Medical Internet Research 8 (2006)

[12] Fischer, M.A., Vogeli, C., Stedman, M.R., Ferries, T.G., Weissman, J.S.: Uptake of Electronic Prescribing In Community-Based Practices. Journal of General Internal Medicine 23, 358-363 (2008)

[13] Cronk, M.C., Fitzgerald, E.P.: Understanding "IS Business Value": Derivation of Dimensions. Logistics Information Management 12, 40-49 (1999)

[14] Davern, M., Kauffman, R.: Discovering Potential and Realizing Value from Information Technology Investments. Journal of Management Information Systems 16, 121-143 (2000)

[15] Gable, G.: Re-Conceptualizing Information System Success: The IS-Impact Measurement Model. Journal of The Association For Information Systems 9, 377-408 (2008)

[16] Mason, R.O.: Measuring Information Output: A Communication Systems Approach. Information and Management 1, 219-234 (1978)

[17] Day, E., Crask, M.R.: Value Assessment: The Antecedent Of Customer Satisfaction. Journal of Consumer Satisfaction Dissatisfaction and Complaining Behavior 13, 52-60 (2000)

[18] Delone, W.H., Mclean, E.R.: Information Systems Success: The Quest for the Dependent Variable. Information Systems Research 3, 60-95 (1992)

[19] Iivari, J., Ervasti, I.: User Information Satisfaction: IS Implementability and Effectiveness. Information and Management 2, 205-220 (1994)

[20] Hu, F.L., Chuang, C.C.: A Study of the Relationship Between the Value Perception and Loyalty Intention Toward an E-Retailer Website. Journal of Internet Banking \& Commerce 17 (2012)

[21] Woodruff, R.B.: Customer Value: The Next Source for Competitive Advantage. Journal of the Academy of Marketing Science 25, 139-153 (1997)

[22] Meijers, J.M., Janssen, M.A., Cummings, G., Wallin, L., Estabrooks, C.A., Halfens, R.Y.: Assessing the Relationships Between Contextual Factors and Research Utilization in Nursing: Systematic Literature Review. Journal of Advanced Nursing 55, 622-635 (2006) 
[23] Fjerrnestad, J., Hiltz, S.R.: Experimental Studies of Group Decision Support Systems: An Assessment of Variables Studied and Methodology. In: Proceedings of the Thirtieth Hawaii International Conference on System Sciences, pp. 45-65. IEEE (1997)

[24] Rigby, M., Roberts, R., Thick, M.: Taking Health Telematics into the 21st Century. The Radcliffe Press (2000)

[25] Chiasson, M.W., Davidson, E.: Pushing the Contextual Envelope: Developing and Diffusing IS Theory for Health Information Systems Research. Information and Organization 14, 155-188 (2004)

[26] Lyons, M., Woloshynowych, M., Adams, S., Vincent, C.: Error Reduction in Medicine. Final Report to the Nuffield Trust (2005)

[27] Kay, M.J.: Healthcare Marketing: What is Salient? International Journal of Pharmaceutical and Healthcare Marketing 1, 247-263 (2007)

[28] Chiu, C.M., Hsu, M.H., Sun, S.Y., Lin, T.C., Sun, P.C.: Usability, Quality, Value and ELearning Continuance Decisions. Computers and Education 45, 399-416 (2005)

[29] Sanchez-Fernandez, R., Iniesta-Bonillo, M.A.: The Concept of Perceived Value: A Systematic Review of the Research. Marketing Theory 7, 427-451 (2007)

[30] Halinen, A., Jaakkola, E.: Marketing in Professional Services Firms: Turning Expertise into Customer Perceived Value. In: Handbook of Research on Entrepreneurship in Professional Services, vol. 219 (2012)

[31] Williams, R.: Change and Stability in Values and Value Systems: A Sociological Perspective. Free Press, New York (1979)

[32] Fritzsche, D., Oz, E.: Personal Values' Influence on the Ethical Dimension of Decision Making. Journal of Business Ethics 75, 335-343 (2007)

[33] Adler, N.J.: International Dimensions of Organizational Behavior. South-Western College Publishing, Cincinnati (2002)

[34] Holbrook, M.B.: The Nature of Customer Value: An Axiology of Services in the Consumption Experience. Service Quality: New Directions in Theory and Practice 21, 21-71 (1994)

[35] Babin, B.J., Darden, W.R., Griffin, M.: Work and/or Fun: Measuring Hedonic and Utilitarian Shopping Value. Journal of Consumer Research 20, 644-656 (1994)

[36] Chou, T.C., Chen, J.R., Pu, C.K.: Exploring the Collective Actions of Public Servants in E-Government Development. Decision Support Systems 45, 251-265 (2008)

[37] Ryan, R.M., Deci, E.L.: Self-Determination Theory and the Facilitation of Intrinsic Motivation, Social Development, and Well-Being. American Psychologist 55, 68-78 (2000)

[38] Leidner, D.E., Kayworth, T.: Review: A Review of Culture in Information Systems Research: Toward a Theory of Information Technology Culture Conflict. MIS Quarterly 30, 357-399 (2006)

[39] Schein, E.H.: Organizational Culture and Leadership: A Dynamic View. Jossey-Bass, San Francisco (1985)

[40] Straub, D., Keil, M., Brenner, W.: Testing the Technology Acceptance Model Across Cultures: A Three Country Study. Information and Management 33, 1-11 (1997)

[41] Anandarajan, M., Igbaria, M., Anakwe, U.P.: IT Acceptance in a Less-Developed Country: A Motivational Factor Perspective. International Journal of Information Management 22, 47-65 (2002)

[42] Bankole, F.O., Bankole, O.O., Brown, I.: Mobile Banking Adoption in Nigeria. The Electronic Journal of Information Systems in Developing Countries 47 (2011)

[43] Hofstede, G.: Culture's Consequences: International Differences in Work-Related Values. Sage, Beverly Hills (1980) 
[44] Hofstede, G.: The Cultural Relativity of Organizational Practices and Theories. Journal of International Business Studies 14, 75-89 (1983)

[45] Van Der Heijden, H.: User Acceptance of Hedonic Information Systems. MIS Quarterly 28, 695-704 (2004)

[46] Safran, C., Golberg, H.: Electronic Patient Records and the Impact of the Internet. International Journal of Medical Informatics 60, 77-83 (2000)

[47] Hunt, D.L., Haynes, R.B., Hanna, S.E., Smith, K.: Effects of Computer-Based Clinical Decision Support Systems on Physician Performance and Patient Outcomes. JAMA: The Journal of the American Medical Association 280, 1339-1346 (1998)

[48] Miller, R.A., Gardner, R.M., Johnson, K.B., Hripcsak, G.: Clinical Decision Support and Electronic Prescribing Systems. Journal of the American Medical Informatics Association 12, 403-409 (2005)

[49] Venkatesh, V., Thong, J., Xu, X.: Consumer Acceptance and Use of Information Technology: Extending the Unified Theory of Acceptance and Use of Technology. MIS Quarterly 36, 157-178 (2012)

[50] Venkatesh, V., Morris, M.G., Davis, G.B., Davis, F.D.: User Acceptance of Information Technology: Toward a Unified View. MIS Quarterly 27, 425-478 (2003)

[51] Sheth, J., Newman, B., Gross, B.: Consumption Values and Market Choices: Theory and Applications. South-Western, Cincinnati (1991)

[52] Pura, M.: Linking Perceived Value and Loyalty in Location-Based Mobile Services. Managing Service Quality 15, 509-538 (2005)

[53] Sweeney, J.C., Soutar, G.N.: Consumer Perceived Value: The Development of a Multiple Item Scale. Journal of Retailing 77, 203-220 (2001)

[54] Venkatesh, V., Morris, M.G.: Why Don't Men Ever Stop to Ask For Directions? Gender, Social Influence, and their Role in Technology Acceptance and Usage Behavior. MIS Quarterly 24, 115-139 (2000)

[55] Schwartz, S.: Universals in the Content and Structure of Values: Theoretical Advances and Empirical Tests in 20 Countries. In: Advances in Experimental Social Psychology. Academic Press, San Diego (1992)

[56] Ke, W., Zhang, P.: The Effects of Extrinsic Motivations and Satisfaction in Open Source Software Development. Journal of the Association for Information Systems 11, 784-808 (2010) 